\title{
Mathematical Analysis of the Reduction of Wüstite at Different Basicity Using Factorial Design
}

\author{
E. A. Mousa ${ }^{1,2}$ \\ ${ }^{1}$ Pyrometallurgy Department, Central Metallurgical Research and Development Institute (CMRDI), El-Felezzat Street 1, \\ P.O. Box 87, El-Tebbin, Helwan, Cairo 11422, Egypt \\ ${ }^{2}$ Institute of Ferrous Metallurgy (IEHK), RWTH Aachen University, 52056 Aachen, Germany \\ Correspondence should be addressed to E. A. Mousa; mousa71@yahoo.com
}

Received 15 September 2014; Revised 20 November 2014; Accepted 3 December 2014; Published 16 December 2014

Academic Editor: Stefano Gialanella

Copyright (c) 2014 E. A. Mousa. This is an open access article distributed under the Creative Commons Attribution License, which permits unrestricted use, distribution, and reproduction in any medium, provided the original work is properly cited.

\begin{abstract}
Numerical prediction is performed on the reduction of wüstite under simulated blast furnace conditions using factorial design approach. Wüstite sinter samples with different basicity $(0.5,1.0$, and 2.0$)$ are reduced with a gas mixture consisting of $30 \% \mathrm{CO}$, $10 \% \mathrm{H}_{2}, 5 \% \mathrm{CO}_{2}$, and $55 \% \mathrm{~N}_{2}$ at $950-1100^{\circ} \mathrm{C}$. In all cases, the reduction degree of wüstite increased with basicity and temperature. A $2^{3}$ factorial design is applied to derive a regression model based on the experimental data of acidic $\left(\mathrm{CaO} / \mathrm{SiO}_{2}=0.5\right)$ and basic $\left(\mathrm{CaO} / \mathrm{SiO}_{2}=2.0\right)$ wüstite which is reduced at $950^{\circ} \mathrm{C}$ and $1100^{\circ} \mathrm{C}$ for 5 and $35 \mathrm{~min}$. The developed mathematical model is applied to predict the reduction degree of wüstite at different basicity $(0.5,1.0$, and 2.0$)$, interval of time (5-35 min), and temperatures (950, $1000,1050^{\circ} \mathrm{C}$, and $1100^{\circ} \mathrm{C}$ ). In general, the results of the driven models are found to be in good agreement with the experimental data of reduction of wüstite in many cases. The MATLAB program is used to carry out the required calculations.
\end{abstract}

\section{Introduction}

The use of mathematical models in the experimental analysis has increased over the years due to its efficiency in explaining, predicting, and controlling the processes [1]. Recently, the factorial design offers an efficient method that can be used to estimate not only the effect of each individual parameter but also the interaction combination of different operational parameters on the overall process [2]. In the blast furnace, the reduction step from wüstite to metallic iron is considered the rate controlling step which has a great influence on the coke consumption and the blast furnace efficiency. Therefore, many studies have been carried out to estimate the reduction kinetics and mechanism of wüstite to metallic iron. The effect of basicity on the reduction behavior of wüstite sinter was studied [3]. The reduction rate was the highest in basic wüstite sinter due to the formation of highly reducible calcium ferrites while the acidic wüstite exhibited the lowest reduction due to the formation of hardly reducible fayalite and ferrobustamite phases. The reduction of basic sinter and acidic pellets under simulated blast furnace condition has been studied [4-6]. The acidic sinter showed higher reduction rate compared to that of basic sinter at the initial stages due to the higher porosity. As the reduction proceeded, the formation of fayalite phase adversely affected the reduction of pellets. The influence of fluxing oxides $(\mathrm{CaO}$ and/or $\mathrm{MgO}$ ) on the reduction of wüstite was examined [7]. The reduction of wüstite to metallic iron was promoted in presence of fluxing oxides at the early stages of reduction, while a slowdown was observed at the latter stages due to the formation of magnesiowüstite. Another study which was carried on pure and wüstite doped with $\mathrm{CaO} / \mathrm{SiO}_{2}$ (basicity ratio: $0.2,0.5$, and 0.8 ) indicated that the reduction decreased as the basicity increased [8]. The effect of $\mathrm{SiO}_{2}$ and/or $\mathrm{Al}_{2} \mathrm{O}_{3}$ on the reduction of wüstite was investigated [9]. The $\mathrm{Al}_{2} \mathrm{O}_{3}$ was found to decrease the reduction rate in the whole range of applied temperature, $670-930^{\circ} \mathrm{C}$. On the other hand, the simultaneous dissolution of $\mathrm{SiO}_{2}$ and $\mathrm{Al}_{2} \mathrm{O}_{3}$ in wüstite resulted in acceleration of the reduction process. The influence of temperature and gas composition on the reduction of wüstite was studied [10]. It was reported that the effect of temperature on increasing the reduction rate of wüstite was significant as the reduction proceeded while the effect of gas composition was not clear all over 
the reduction process. The reduction of wüstite by $\mathrm{H}_{2}$ gas at $450-600^{\circ} \mathrm{C}$ was investigated [11]. The reduction mechanism was found to be dependent on the eutectoid decomposition temperature at $530^{\circ} \mathrm{C}$. At temperature higher than $530^{\circ} \mathrm{C}$, wüstite was reduced directly to metallic iron while at lower temperature the reduction was accomplished through two sequential steps: (i) decomposition of wüstite to magnetite and metallic iron $\left(4 \mathrm{FeO}=\mathrm{Fe}_{3} \mathrm{O}_{4}+\mathrm{Fe}\right)$; (ii) reduction of magnetite with $\mathrm{H}_{2}$ to metallic iron $\left(\mathrm{Fe}_{3} \mathrm{O}_{4}+4 \mathrm{H}_{2}=3 \mathrm{Fe}+\right.$ $4 \mathrm{H}_{2} \mathrm{O}$ ). In the reduction of dense wüstite with $\mathrm{H}_{2}$ at $670-$ $930^{\circ} \mathrm{C}$, it was reported that a small addition of $\mathrm{SiO}_{2}(0.2 \%)$ promoted the reducibility of wüstite at $>800^{\circ} \mathrm{C}$, while it decreased the reduction at $<730^{\circ} \mathrm{C}[9]$.

The previous survey summarized some studies that have been carried out experimentally to elucidate the effect of some factors on the reduction rate of wüstite. However, the effective magnitude of these factors either individually or collectively on the reduction rate of wüstite sinter is still not clear. This can be carried out by the application of statistical factorial design approach which has several advantages in highlighting the effect of individual variables and their relative importance on the reduction process $[12,13]$. In the current study, a $2^{3}$ factorial design is used to precisely estimate the individual and mutual interactions of three main parameters including basicity, interval of time, and temperature on the reduction rate of wüstite sinter. The effect of other parameters such as impurities $\left(\mathrm{MgO}, \mathrm{Al}_{2} \mathrm{O}_{3}, \mathrm{MnO}_{2}\right.$, $\mathrm{TiO}_{2}$, and $\mathrm{BaO}$ ), sample size and shape, gas composition, and porosity will be considered in further investigations. The current factorial design is built on the experimental data of wüstite sinter which has different basicity $\left(\mathrm{CaO} / \mathrm{SiO}_{2}: 0.5\right.$, 1.0, and 2.0) and reduced with simulated blast furnace shaft gas $\left(30 \% \mathrm{CO} ; 10 \% \mathrm{H}_{2} ; 5 \% \mathrm{CO}_{2} ; 55 \% \mathrm{~N}_{2}\right)$ at $950-1100^{\circ} \mathrm{C}$. The calculations have been carried out by MATLAB program.

\section{Materials and Methods}

In the current study, pure chemical $\mathrm{Fe}_{2} \mathrm{O}_{3}, \mathrm{CaO}$, and $\mathrm{SiO}_{2}$ were used to eliminate the effect of other impurities which normally exist in the iron ore and affect the reduction process. Pure sinter mixtures with different basicity $\left(\mathrm{CaO} / \mathrm{SiO}_{2}: 0.5\right.$, 1.0, and 2.0) are prepared. The acidic mixture with basicity equal to 0.5 consisted of $85 \% \mathrm{Fe}_{2} \mathrm{O}_{3}, 5 \% \mathrm{CaO}$, and $10 \% \mathrm{SiO}_{2}$. The neutral mixture with basicity equal to 1.0 is composed of $85 \% \mathrm{Fe}_{2} \mathrm{O}_{3}, 7.5 \% \mathrm{CaO}$, and $7.5 \% \mathrm{SiO}_{2}$. The basic mixture with basicity equal to 2.0 consists of $85 \% \mathrm{Fe}_{2} \mathrm{O}_{3}, 10 \% \mathrm{CaO}$, and $5 \% \mathrm{SiO}_{2}$. The oxide powders were mixed well in a ballmill to guarantee the complete homogeneity of the mixtures. Equal weights of $\sim 2.0 \mathrm{~g}$ of each mixture were pressed in a cylindrical mould of $\sim 1.0 \mathrm{~cm}$ inner diameter at $10 \mathrm{kN}$ using a hydraulic press. Under these conditions equal size compacts (diameter $=0.99 \mathrm{~cm}$ and height $=1.0 \mathrm{~cm}$ ) have been prepared. The compacts were dried at $100^{\circ} \mathrm{C}$ for 24 hours, then fired in a muffle furnace up to $1300^{\circ} \mathrm{C}$ with heating rate $10 \mathrm{~K} / \mathrm{min}$, and kept at this temperature for $1.0 \mathrm{~h}$ to ensure the complete reactions between different oxides $\left(\mathrm{Fe}_{2} \mathrm{O}_{3}, \mathrm{CaO}\right.$, and $\left.\mathrm{SiO}_{2}\right)$. The prepared sinters (acidic, neutral, and basic) were fast cooled down in air to room temperature and then kept in a desiccator for subsequent reduction experiments.

The reduction experiments have been carried out in a vertical tube furnace as shown in Figure 1. The system consisted of an automatic sensitive balance (B) equipped with a vertical tube furnace $(\mathrm{F})$. Alumina reaction tube (A) was fitted inside the furnace. The output of the balance $(\mathrm{O})$ was connected to the recording system (R) for continuous measuring of the total weight loss during the reduction process as a function of time. The flow rate and the composition of the reduced gas are adjusted through digital flow meters (D). The actual temperatures of the furnace (T1) and sample (T2) were measured with controller (K). Purified $\mathrm{N}_{2}$ at constant flow rate of $1.0 \mathrm{liter} / \mathrm{min}$ was introduced into the reaction tube during the heating up of the furnace. At the applied temperature, the sintered compact (C) was placed in a platinum basket $(\mathrm{P})$ and suspended from the balance arm by platinum wire (W). The sinter sample was positioned in the reaction tube at the middle of hot zone. After soaking the sample at $900^{\circ} \mathrm{C}$ for 10 minutes, a gas composition which consists of $20 \% \mathrm{CO}, 20 \% \mathrm{CO}_{2}, 5 \% \mathrm{H}_{2}$, and $55 \% \mathrm{~N}_{2}$ was applied for the prereduction of sinters to wüstite. After reaching a constant weight, the temperature was increased to 950, 1000, 1050 , or $1100^{\circ} \mathrm{C}$ in presence of pure $\mathrm{N}_{2}$. The reduction of wüstite is started with gas mixture consisting of $30 \% \mathrm{CO}$, $5.0 \% \mathrm{CO}_{2}, 10 \% \mathrm{H}_{2}$, and $55 \% \mathrm{~N}_{2}$. Both gas mixtures which are applied for prereduction of sinter to wüstite and the further reduction of wüstite to metallic iron are selected to simulate the gas composition in the blast furnace at the upper and lower shaft. The flow rate of gas mixture was always constant at 1.0 liter/min. During the reduction experiment, the weight loss was continuously recorded as a function of time till the sample weight became constant. At the end of experiment, the reduced sinter was pulled up to the cooled zone of the reaction tube in presence of purified $\mathrm{N}_{2}$ flow and dropped out, by releasing the suspension wire from the balance, into a conical flask containing acetone to prevent the reoxidation. The reduction degree of wüstite was calculated based on the following:

$$
R_{w}, \%=\frac{\left(W_{i}-W_{f}\right)}{W_{t}} * 100,
$$

where $R_{w}$ is the reduction degree of wüstite, $W_{i}$ the initial weight of wüstite sample before reduction, $W_{f}$ the final weight of sample after reduction, and $W_{t}$ the total weight loss when the sample is completely reduced.

\section{Results and Discussion}

3.1. Experimental Results. The sinter samples which prereduced to wüstite with $20 \% \mathrm{CO}, 20 \% \mathrm{CO}_{2}, 5 \% \mathrm{H}_{2}$, and $55 \%$ $\mathrm{N}_{2}$ at $900^{\circ} \mathrm{C}$ were subsequently reduced with $30 \% \mathrm{CO}, 5 \%$ $\mathrm{CO}_{2}, 10 \% \mathrm{H}_{2}$, and $55 \% \mathrm{~N}_{2}$ at $950-1100^{\circ} \mathrm{C}$. The reduction curves of wüstite sinters at $950^{\circ} \mathrm{C}, 1000^{\circ} \mathrm{C}, 1050^{\circ} \mathrm{C}$, and $1100^{\circ} \mathrm{C}$ are given in Figures 2(a)-2(d), respectively. At each applied temperature, the highest reduction degree and reduction rate are exhibited in basic wüstite sinter $\left(\mathrm{B}=\mathrm{CaO} / \mathrm{SiO}_{2}=2.0\right)$ followed by neutral wüstite sinter $\left(\mathrm{B}=\mathrm{CaO} / \mathrm{SiO}_{2}=1.0\right)$ and 


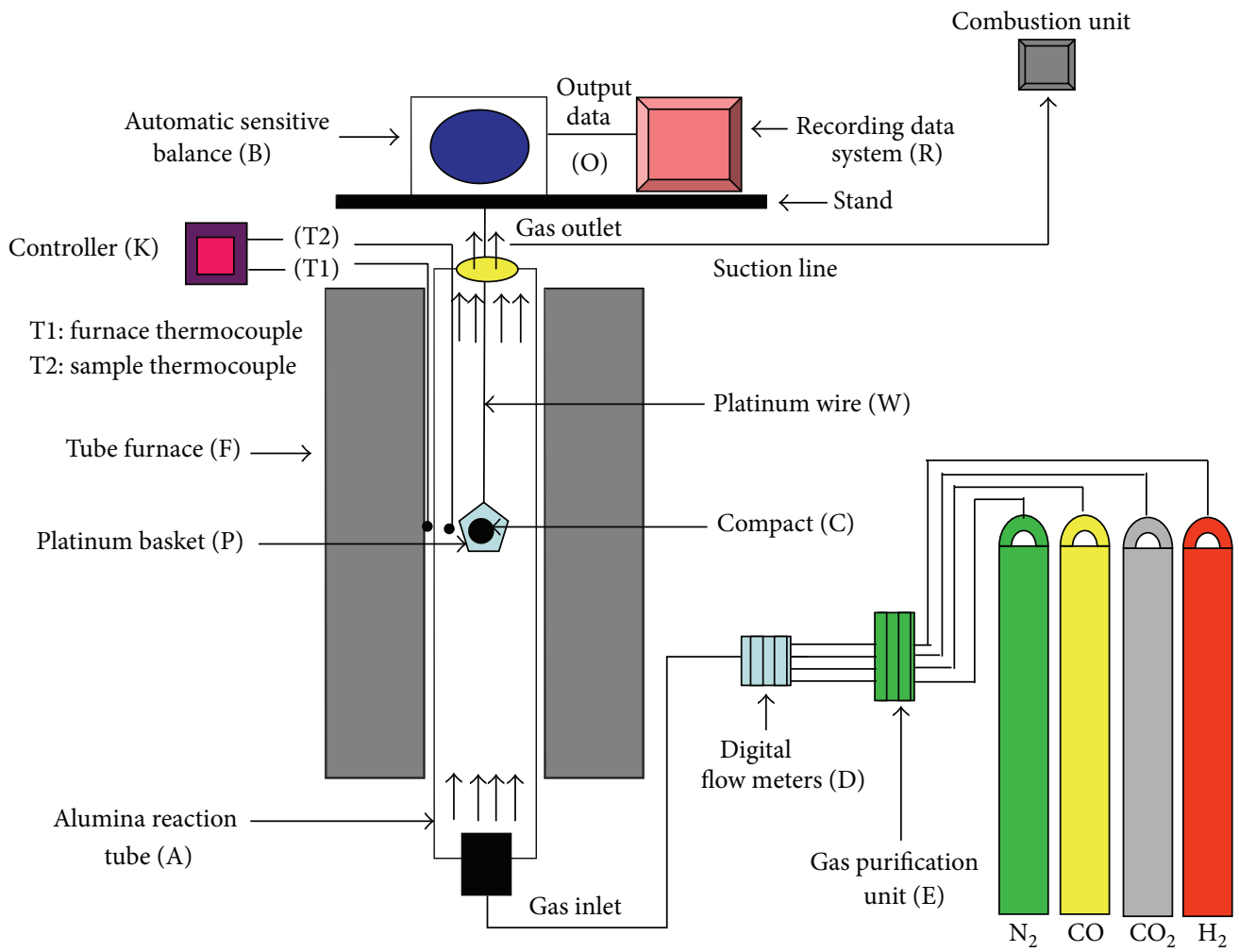

FIgURE 1: Schematic diagram of reduction system.

TABLE 1: Conditions of experiments and reduction degree of wüstite sinter.

\begin{tabular}{lcccccc}
\hline Trail number Basicity & Time, min & Temperature, ${ }^{\circ} \mathrm{C}$ & Reduction degree, \%; 1st & Reduction degree, \%; 2nd & Reduction degree, \%; average \\
\hline 1 & 0.5 & 5 & 950 & 37.1135 & 36.9957 & 37.0546 \\
2 & 2.0 & 5 & 950 & 47.8015 & 47.6659 & 47.7337 \\
3 & 0.5 & 35 & 950 & 64.0251 & 63.8383 & 63.9317 \\
4 & 2.0 & 35 & 950 & 89.3165 & 89.1381 & 89.2273 \\
5 & 0.5 & 5 & 1100 & 47.8021 & 47.6653 & 47.7337 \\
6 & 2.0 & 5 & 1100 & 72.1252 & 71.7068 & 71.9160 \\
7 & 0.5 & 35 & 1100 & 83.0875 & 82.7623 & 82.9249 \\
8 & 2.0 & 35 & 1100 & 99.7213 & 99.4791 & 99.6002 \\
\hline
\end{tabular}

finally acidic wüstite sinter $\left(\mathrm{B}=\mathrm{CaO} / \mathrm{SiO}_{2}=0.5\right)$. The higher reduction rate of basic wüstite sinter was attributed to the formation of highly reducible calcium ferrites on account of wüstite $\left(2 \mathrm{CaO}+3 \mathrm{FeO} \rightarrow 2 \mathrm{CaO} \cdot \mathrm{Fe}_{2} \mathrm{O}_{3}+\mathrm{Fe}\right)$, while the lower reduction rate of acidic wüstite sinter was attributed to the formation of hard reducible fayalite $\left(2 \mathrm{FeO} \cdot \mathrm{SiO}_{2}\right)$ and ferrobustamite $\left(\left(\mathrm{Ca}_{0.5} \mathrm{Fe}_{0.5}\right) \mathrm{SiO}_{3}\right)$ phases. The reduction kinetics and mechanism of highly basic and acidic wüstite were thoroughly discussed elsewhere [3]. In the current study, a $2^{3}$ factorial design is applied to the experimental data of wüstite sinter at the highest and lowest basicity $(B=0.5$ and 2.0 ) and temperature $\left(950^{\circ} \mathrm{C}\right.$ and $\left.1100^{\circ} \mathrm{C}\right)$. The reduction time is selected at 5 and $35 \mathrm{~min}$ which represent the initial and moderate reduction stages. Each trail was repeated two times under the same conditions in order to confirm the results reproducibility. The experimental data are given in Table 1.

\subsection{Model Description}

3.2.1. Definition of the Controlling Parameters. The controlling parameters which are considered in the current applied $2^{3}$ factorial design are including the effect of basicity $\left(\mathrm{CaO} / \mathrm{SiO}_{2}\right)$, reduction time, and temperature on reduction process of wüstite sinter.

By convention, the effect of a factor was denoted by a capital Latin letter. Thus " $A$ " refers to the effect basicity $\left(\mathrm{CaO} / \mathrm{SiO}_{2}\right)$, " $B$ " refers to the effect of time, " $C$ " refers to the effect of reduction temperature, " $A B$ " refers to the interaction effect of basicity and time, " $A C$ " refers to interaction effect of basicity and temperature, and " $B C$ " refers to the interaction effect of time and temperature, while " $A B C$ " refers to the interaction effect of basicity, time, and temperature. The low and high levels of $A, B$, and $C$ are denoted by "-" and "+", 


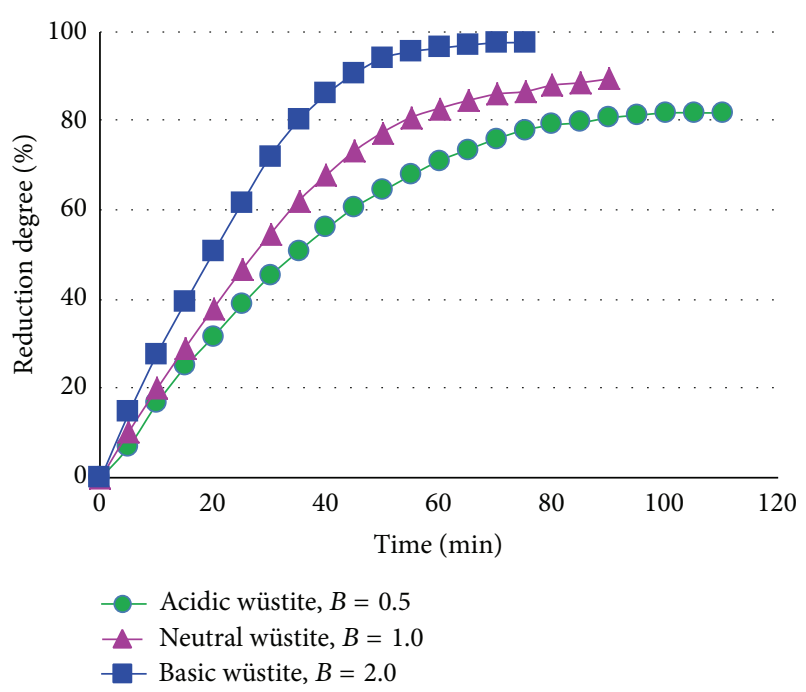

(a)

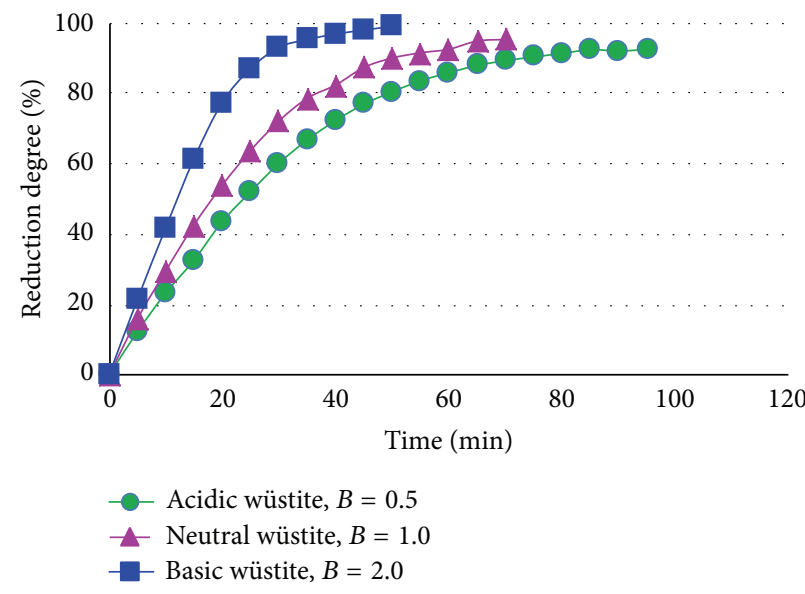

(c)

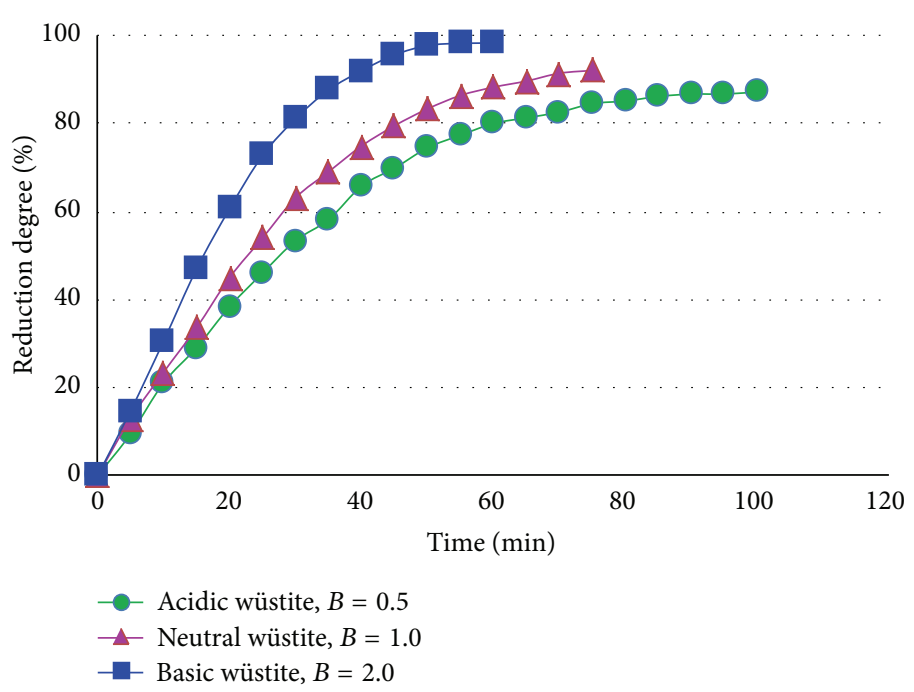

(b)

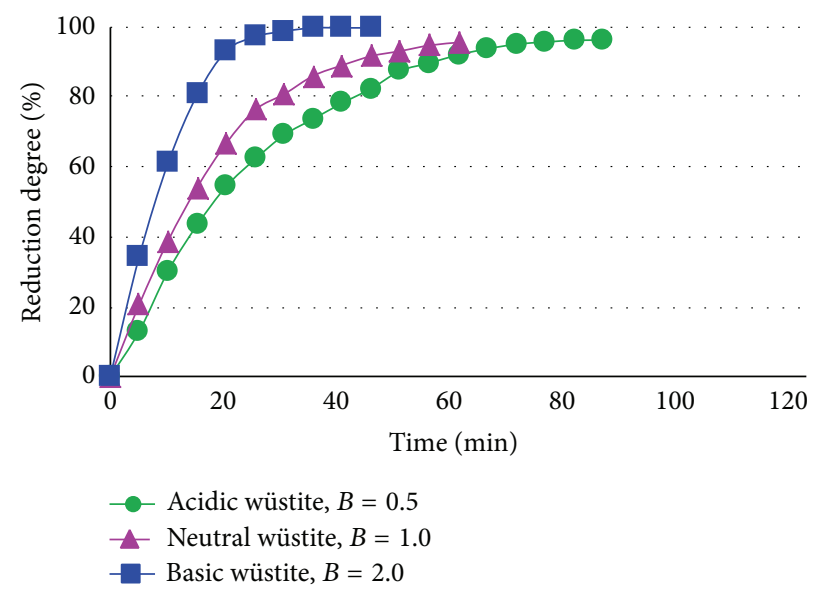

(d)

Figure 2: Comparison between the reduction curves of different basis sinter reduced at (a) $950^{\circ} \mathrm{C}$, (b) $1000^{\circ} \mathrm{C}$, (c) $1050^{\circ} \mathrm{C}$, and (d) $1100^{\circ} \mathrm{C}$.

respectively. The eight treatment combinations in the design are usually represented by lowercase letters. The high level of any factor in the treatment combination is denoted by the corresponding lowercase letter $(a, b, c, a b, a c, b c$, and $a b c)$, while the low level of any factor will be indicated by the absence of its corresponding letter. Thus, " $a$ " represents the treatment combination of $A$ (basicity) at high level with $B$ (time) and $C$ (temperature) at low levels, " $b$ " represents $B$ at high level with $A$ and $C$ at low levels, " $a b$ " represents $A$ and $B$ factors at the high levels with $C$ at low level, " $a c$ " represents $A$ and $C$ at high levels with $B$ at low level, " $b c$ " represents $B$ and $C$ at high levels with $A$ at low level, " $a b c$ " represents $A, B$, and $C$ factors at the high levels, and finally (1) is used to denote all of the factors at low level.

The average effect of any factor can be defined as the change in response produced by a change in the level of that factor averaged over the levels of the other factors.
The symbols (1), $a, b, a b, c, a c, b c$, and $a b c$ represent the total of all 2 replicates taken at the treatment combination, that is, $(n=2)$.

3.2.2. Mathematical Formulations. Mathematical formulations are used to estimate the effect of different parameters on the reduction degree of wüstite sinter. The effect of $A$ at low levels of $B$ and $C$ is $[a-(1)] / n$, the effect of $A$ at high levels of $B$ and $C$ is $[a b c-b c] / n$, the effect of $A$ at low level of $B$ and high level of $C$ is $[a c-c] / n$, and the effect of $A$ at high level of $B$ and low level of $C$ is $[a b-b] / n$. The main effect of $A$ is the average quantities of its effect at low and high levels of $B$ and $C$ as given in the following:

$$
A=\frac{1}{4 n}[(a+a b+a c+a b c)-((1)+b c+c+b)] .
$$


TABLE 2: Algebraic signs for calculating effects in the $2^{3}$ design.

\begin{tabular}{|c|c|c|c|c|c|c|c|c|}
\hline \multirow{2}{*}{ Treatment combination } & \multicolumn{8}{|c|}{ Factorial effect } \\
\hline & $I$ & $A$ & $B$ & $A B$ & C & $A C$ & $B C$ & $A B C$ \\
\hline (1) & + & - & - & + & - & + & + & - \\
\hline$a$ & + & + & - & - & - & - & + & + \\
\hline$b$ & + & - & + & - & - & + & - & + \\
\hline$a b$ & + & + & + & + & - & - & - & - \\
\hline$c$ & + & - & - & + & + & - & - & + \\
\hline$a c$ & + & + & - & - & + & + & - & - \\
\hline$b c$ & + & - & + & - & + & - & + & - \\
\hline$a b c$ & + & + & + & + & + & + & + & + \\
\hline
\end{tabular}

The average main effect of $B$ and $C$ can be calculated in the same manner of $A$ as given in the following:

$$
\begin{aligned}
& B=\frac{1}{4 n}[(b+a b+b c+a b c)-((1)+a+a c+c)], \\
& C=\frac{1}{4 n}[(c+a c+b c+a b c)-((1)+a+b+a b)] .
\end{aligned}
$$

The interaction effect of $A B$ is one half of the difference between the averages of $A$ effect at the two levels of $B$. The average effect of $A$ at high level of $B$ is $[(a b c-b c)+(a b-b)] / 2 n$, and the average effect of $A$ at low level of $B$ is $[(a c-c)+$ $(a-(1))] / 2 n$. Based on this, the interaction AB effect can be given in the following:

$$
A B=\frac{1}{4 n}[(a b c+a b+c+(1))-(b c+b+a c+a)] .
$$

In similar way, the average effect of $A C$ and $B C$ can be calculated as give in the following:

$$
\begin{aligned}
& A C=\frac{1}{4 n}[(a b c+a c+b+(1))-(a b+c+b c+a)], \\
& B C=\frac{1}{4 n}[(a b c+b c+a+(1))-(a c+b+a b+c)] .
\end{aligned}
$$

The $A B C$ interaction effect is defined as the average difference between the $A B$ interaction for the two different levels of $C$ as given in the following:

$$
\begin{aligned}
& A B C \\
& \quad=\frac{1}{4 n}[(a b c-b c)-(a c-c)-(a b-b)+(a-(1))],
\end{aligned}
$$

$A B C$

$$
=\frac{1}{4 n}[(a b c+c+b+a)-(b c+a c+a b+(1))] .
$$

3.3. Model Application. Table 2 summarizes the plus and minus signs that can be developed from the contrasts, where the high level is referred to by plus sign $(+)$ and low level is referred to by minus sign (-). The signs of identity element (1) are plus.

Sum of squares for the effects in the $2^{3}$ design with $n$ replicates is $\mathrm{SS}=(\text { Contrast })^{2} / 8 n$. The total sum of squares
$\left(\mathrm{SS}_{T}\right)$ has $(a b c n-1)$ degrees of freedom and the error sum of squares $\left(\mathrm{SS}_{E}\right)$ has $a b c(n-1)$ degrees of freedom. They can be calculated by using (9) and (10), respectively. Table 3 summarizes the main effects of variables, sum of squares, and the mean square:

$$
\begin{aligned}
\mathrm{SS}_{T}= & \sum_{i=1}^{2} \sum_{j=1}^{2} \sum_{k=1}^{2} \sum_{n=1}^{n} y_{i j k}^{2}-\frac{x^{2}}{4 n} \\
\mathrm{SS}_{E}= & \mathrm{SS}_{T}-\mathrm{SS}_{A}-\mathrm{SS}_{B}-\mathrm{SS}_{C}-\mathrm{SS}_{A B}-\mathrm{SS}_{A C} \\
& -\mathrm{SS}_{B C}-\mathrm{SS}_{A B C},
\end{aligned}
$$

where $y$ is the reduction degree observation and $x$ is the mean reduction degree of all observation.

From the data given in Table 3 , it can be seen that the highest positive effect on the reduction degree of wüstite is exhibited by the interval of time followed by the basicity and then the applied temperature. The binary interaction between the parameters showed the highest positive effect on the reduction of wüstite for basicity with time followed by time with temperature and then basicity with temperature. The ternary interaction between the basicity, time, and temperature exhibited a negative effect on the reduction degree of wüstite.

The contrast coefficients which are used to estimate the effects are summarized in Table 4 . The contrast coefficient is always either $(+1)$ or $(-1)$ which is referring to the maximum and minimum level of the affecting factor.

The results of the experiment can be expressed in terms of regression model. The regression model is given in the following:

$$
\begin{aligned}
\mathrm{RD}= & \beta_{0}+\beta_{1} x_{1}+\beta_{2} x_{2}+\beta_{3} x_{3}+\beta_{12} x_{1} x_{2}+\beta_{13} x_{1} x_{3} \\
& +\beta_{23} x_{2} x_{3}+\beta_{123} x_{1} x_{2} x_{3}+\epsilon,
\end{aligned}
$$

where $\mathrm{RD}$ is the predicted reduction degree, $\% ; x_{1}, x_{2}$, and $x_{3}$ are coded variables that represent the basicity, time, and temperature, respectively. $\beta_{0}$ is the intercept which is the grand average of all 16 observations (i.e., $\beta_{0}=46.6245$ ), the regression coefficients $\beta_{1}, \beta_{2}$, and $\beta_{3}$ are one-half the corresponding factors $A, B$, and $C$, respectively, $\left(\beta_{1}=10.5038\right.$, $\beta_{2}=29.3628$, and $\left.\beta_{3}=8.5234\right)$, the regression coefficients $\beta_{12}, \beta_{13}, \beta_{23}$, and $\beta_{123}$ are one-half the corresponding factors 
TABLE 3: Analysis of variances.

\begin{tabular}{|c|c|c|c|c|c|}
\hline Source of variance & Average effect & Sum of square (SS) & Degree of freedom & Mean of square (MS) & $F_{o}$, magnitude effect \\
\hline$A$ (basicity) & 21.0075275 & 1765.264847 & 1 & 1765.26485 & 41728.19065 \\
\hline$B$ (time) & 58.7255825 & 13794.77616 & 1 & 13794.7762 & 326087.6410 \\
\hline$C$ (temperature) & 17.0467075 & 1162.360946 & 1 & 1162.360946 & 27476.45446 \\
\hline$A B$ & 6.5728625 & 172.8100858 & 1 & 172.8100858 & 4084.969017 \\
\hline$A C$ & 2.6150975 & 27.35493974 & 1 & 27.35493974 & 646.6293955 \\
\hline$B C$ & 4.2312625 & 71.61432938 & 1 & 71.61432938 & 1692.854415 \\
\hline$A B C$ & -4.2479775 & 72.18125136 & 1 & 72.18125136 & 1706.255593 \\
\hline Error & & 0.338431131 & 8 & 0.04230389 & \\
\hline Total & & 17066.70099 & 15 & & \\
\hline
\end{tabular}

TABLE 4: Contrast coefficients of effects.

\begin{tabular}{lcccccccc}
\hline Effects & $(1)$ & $a$ & $b$ & $a b$ & $c$ & $a c$ & $b c$ & $a b c$ \\
\hline$A$ & -1 & +1 & -1 & +1 & -1 & +1 & -1 & +1 \\
$B$ & -1 & -1 & +1 & +1 & -1 & -1 & +1 & +1 \\
$A B$ & +1 & -1 & -1 & +1 & +1 & -1 & -1 & +1 \\
$C$ & -1 & -1 & -1 & -1 & +1 & +1 & +1 & +1 \\
$A C$ & +1 & -1 & +1 & -1 & -1 & +1 & -1 & +1 \\
$B C$ & +1 & +1 & -1 & -1 & -1 & -1 & +1 & +1 \\
$A B C$ & -1 & +1 & +1 & -1 & +1 & -1 & -1 & +1 \\
\hline
\end{tabular}

$A B, A C, B C$, and $A B C$, respectively, which are $\left(\beta_{12}=3.2864\right.$, $\beta_{13}=1.3075, \beta_{23}=2.1156$, and $\left.\beta_{123}=-2.1239\right)$, and $\epsilon$ is the residual (the difference between observed and fitted point of the design). Equation (11) can be given with regression coefficients values as shown in the following:

$$
\begin{aligned}
\mathrm{RD}= & 46.6245+10.5038 x_{1}+29.3628 x_{2}+8.5234 x_{3} \\
& +3.2864 x_{1} x_{2}+1.3075 x_{1} x_{3}+2.1156 x_{2} x_{3} \\
& -2.1239 x_{1} x_{2} x_{3}+\epsilon .
\end{aligned}
$$

To estimate the residual $(\epsilon)$ and to calculate the predicted RD at (1), $a, b, c, a b, a c, b c$, and $a b c$, the sign of coded variables can be taken from Table 2 . The resuts are presented in Table 5. The average residual is \pm 0.12 which can be neglected.

The relation between the natural variable and the coded variable can be given as follows: the coded variable is equal to [(natural variable $-1 / 2$ (variable at high level + variable at low level))/1/2(variable at high level - variable at low level)]. Based on this, the RD can be predicted in terms of basicity, time, and temperature as given in the full regression model formulation in (13). This equation covers basicity from $0.5-$ 2.0 , reduction time 5-35 $\mathrm{min}$, within temperature range 950 $1100^{\circ} \mathrm{C}$ :

$$
\begin{aligned}
\mathrm{RD}= & 14.62044-67.2637 *[B]-3.56005 *[t] \\
& -0.01599 *[T]+2.8722 *[B] *[t] \\
& +0.07358 *[B] *[T]+0.005026 *[t] *[T] \\
& -0.002517 *[B] *[t] *[T],
\end{aligned}
$$

where $B$ is the basicity $\left(\mathrm{CaO} / \mathrm{SiO}_{2}\right), t$ is reduction time in min, and $T$ is the temperature in ${ }^{\circ} \mathrm{C}$.
This full regression formulation indicates that the reduction degree of wüstite sinter is not only affected by the individual parameter (basicity, time, or temperature) but also by the mutual interactions among all of these parameters.

3.4. Validation of the Regression Model. In order to examine the validity and the efficiency of the current regression model the derived equation is used to estimate the reduction degree of wüstite at different basicity $(0.5,1.0$, and 2.0$)$, reduction time $(5,10,15,20,25,30$, and $35 \mathrm{~min})$, and temperatures $\left(950^{\circ} \mathrm{C}, 1000^{\circ} \mathrm{C}, 1050^{\circ} \mathrm{C}\right.$, and $\left.1100^{\circ} \mathrm{C}\right)$. The results are compared to that obtained from the experimental reduction trails as can be seen in Figure 3. It can be seen that the predicted values of the reduction of wüstite are very close and in a good agreement to the average experimetal results at relatively low temperature at $950^{\circ} \mathrm{C}$ and $1000^{\circ} \mathrm{C}$. As the temperature increased $\left(\geq 1050^{\circ} \mathrm{C}\right)$, deviations to different extents appeared and it becomes siginficant at the intermediate stages of reduction of high basic wüstite sinter $(B=2.0)$. This can be attributed to the effect of temperature on the enhancement of the reduction of calcium ferrites which are formed on account of wüstite as shown in the following:

$$
\begin{aligned}
& 2 \mathrm{CaO}+3 \mathrm{FeO} \longrightarrow 2 \mathrm{CaO} \cdot \mathrm{Fe}_{2} \mathrm{O}_{3}+\mathrm{Fe} \\
& 2 \mathrm{CaO} \cdot \mathrm{Fe}_{2} \mathrm{O}_{3}+\mathrm{CO}\left(\mathrm{H}_{2}\right) \\
& \longrightarrow 2 \mathrm{CaO}+2 \mathrm{Fe}+3 \mathrm{CO}_{2}\left(\mathrm{H}_{2} \mathrm{O}\right)
\end{aligned}
$$

Based on the previous findings, the derived regression model is able to predict the reduction values in many cases especially at lower temperature $\left(\leq 1000^{\circ} \mathrm{C}\right)$ and lower basicity. In highly basic wüstite, the formation of calcium ferrites enhanced the reduction rate at high temperature which resulted in a significant deviation compared to that calculated by the regression model.

\section{Conclusions}

In the current study, wüstite sinter with different basicity $\left(\mathrm{CaO} / \mathrm{SiO}_{2}=0.5,1.0\right.$, and 2.0$)$ was prepared and reduced with $30 \% \mathrm{CO}, 5 \% \mathrm{CO}_{2}, 10 \% \mathrm{H}_{2}$, and $55 \% \mathrm{~N}_{2}$ at $950-1100^{\circ} \mathrm{C}$. A $2^{3}$ factorial design is built on the experimetal data of reduction at lowest and highest basicity and reduction tempeartures. The main findings can be summarized in the following points. 
TABLE 5: Actual and predicted reduction degree at different conditions (variables).

\begin{tabular}{|c|c|c|c|c|c|c|}
\hline \multirow{2}{*}{ Variable } & \multirow{2}{*}{ Predicted RD, \% } & \multicolumn{2}{|c|}{ Actual RD, \% } & \multicolumn{2}{|c|}{ Residence $(\epsilon)$} & \multirow{2}{*}{ The residence variation } \\
\hline & & 1st & 2nd & 1st & 2nd & \\
\hline (1) & 8.024465 & 7.14062 & 6.9957 & +0.072 & -0.072 & \pm 0.072 \\
\hline$a$ & 15.58829 & 14.5836 & 14.6959 & -0.056 & +0.056 & \pm 0.056 \\
\hline$b$ & 51.679715 & 50.67498 & 50.8083 & -0.067 & +0.067 & \pm 0.067 \\
\hline$a b$ & 80.89079 & 80.27172 & 79.6381 & +0.32 & -0.320 & \pm 0.32 \\
\hline$c$ & 13.97009 & 12.87576 & 13.1653 & -0.145 & +0.145 & \pm 0.145 \\
\hline$a c$ & 35.25779 & 34.40974 & 34.2268 & +0.091 & -0.091 & \pm 0.091 \\
\hline$b c$ & 74.57909 & 73.54268 & 73.7623 & -0.11 & +0.11 & \pm 0.11 \\
\hline$a b c$ & 100.02429 & 99.7209 & 99.4791 & 0.12 & -0.12 & \pm 0.12 \\
\hline
\end{tabular}

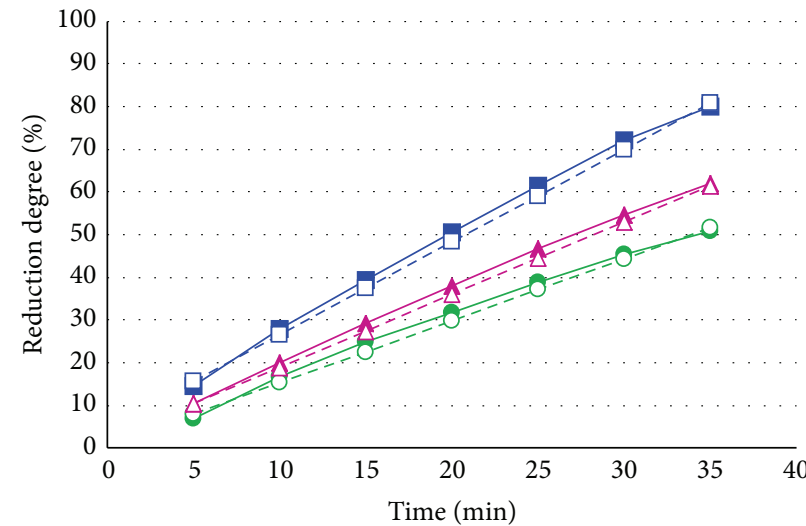

- Experimental acidic wüstite, $B=0.5$

- - - Theoretical acidic wüstite, $B=0.5$

$\triangle$ Experimental neutral wüstite, $B=1.0$

$-\Delta-$ Theoretical neutral wüstite, $B=1.0$

$\rightarrow$ Experimental basic wüstite, $B=2.0$

- - Theoretical basic wüstite, $B=2.0$

(a)

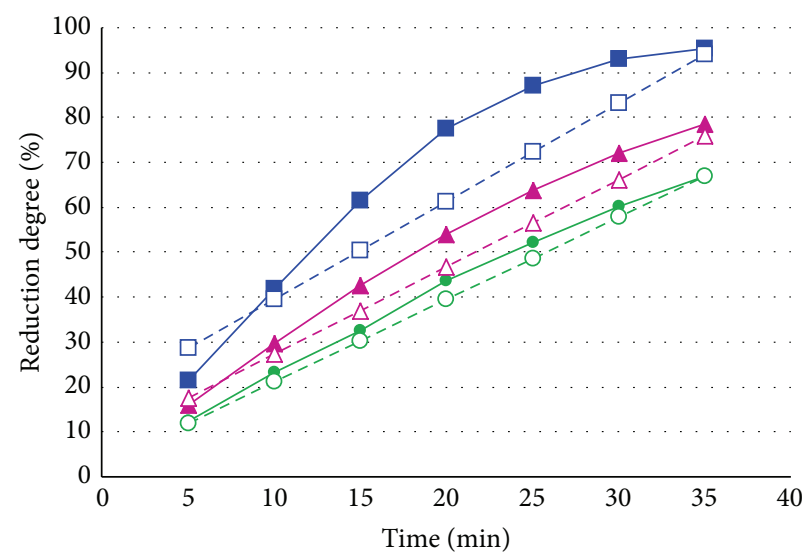

$\rightarrow$ Experimental acidic wüstite, $B=0.5$

- o- Theoretical acidic wüstite, $B=0.5$

$\triangle$ Experimental neutral wüstite, $B=1.0$

$-\Delta-$ Theoretical neutral wüstite, $B=1.0$

$\rightarrow$ Experimental basic wüstite, $B=2.0$

- - Theoretical basic wüstite, $B=2.0$

(c)

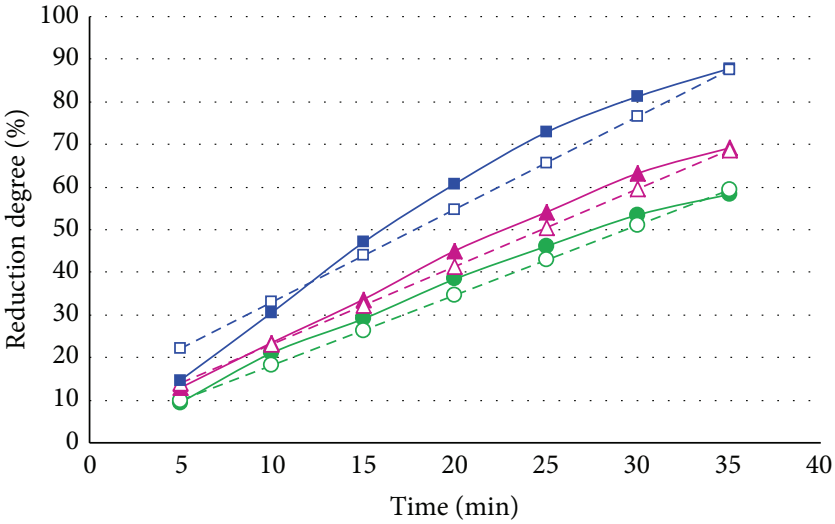

$\longrightarrow$ Experimental acidic wüstite, $B=0.5$

- - - Theoretical acidic wüstite, $B=0.5$

$\triangle$ Experimental neutral wüstite, $B=1.0$

$-\Delta-$ Theoretical neutral wüstite, $B=1.0$

$\rightarrow$ Experimental basic wüstite, $B=2.0$

- - Theoretical basic wüstite, $B=2.0$

(b)

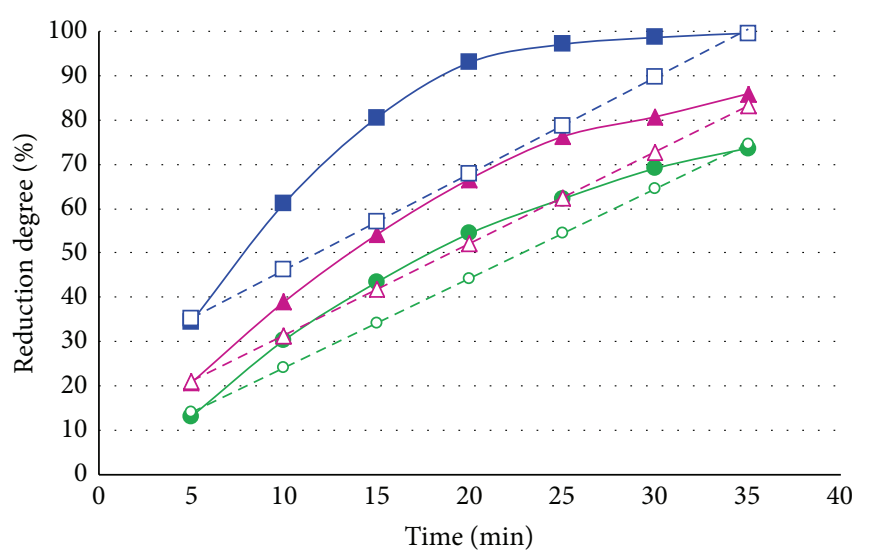

$\longrightarrow$ Experimental acidic wüstite, $B=0.5$

- 0 - Theoretical acidic wüstite, $B=0.5$

$\triangle$ Experimental neutral wüstite, $B=1.0$

$-\Delta-$ Theoretical neutral wüstite, $B=1.0$

$\rightarrow$ Experimental basic wüstite, $B=2.0$

- - Theoretical basic wüstite, $B=2.0$

(d)

Figure 3: Experimental and predicted reduction degree of wüstite with different basicity at (a) $950^{\circ} \mathrm{C}$, (b) $1000^{\circ} \mathrm{C}$, (c) $1050^{\circ} \mathrm{C}$, and (d) $1100^{\circ} \mathrm{C}$. 
(1) The higest reduction degree was exhibited by the basic wüstite sinter $\left(\mathrm{CaO} / \mathrm{SiO}_{2}=2.0\right)$ which followed neutral wustite $\left(\mathrm{CaO} / \mathrm{SiO}_{2}=1.0\right)$ and the lowest by acidic wüstite sinter $\left(\mathrm{CaO} / \mathrm{SiO}_{2}=0.5\right)$.

(2) A full regression formulation was develpoed to calculate the reduction degree $(\mathrm{RD})$ of wüstite based on basicity $(B)$, time $(t)$, and temperature $(T)$ :

$$
\begin{aligned}
\mathrm{RD}= & 14.62044-67.2637 *[B]-3.56005 *[t] \\
& -0.01599 *[T]+2.8722 *[B] *[t] \\
& +0.07358 *[B] *[T]+0.005026 *[t] *[T] \\
& -0.002517 *[B] *[t] *[T] .
\end{aligned}
$$

(3) The highest positive effect on the reduction degree was exhibited by the interval of time followed by basicity and then the applied temperature. In the binary interaction, the basicity with time exhibited the highest positive effect on the reduction of wüstite followed by time with temperature and then basicity with temperature. The ternary interaction between the basicity, time, and temperature showed a negative effect on the reduction degree of wüstite.

(4) The validation of the regression model exhibited a good agreement with the experimental results at relatively low temperature $\left(\leq 1000^{\circ} \mathrm{C}\right)$. A significant deviation was obtained at high temperature $\left(\geq 1050^{\circ} \mathrm{C}\right)$ which was attributed to the formation of highly reducible calcium ferrite phase.

\section{Conflict of Interests}

The author declares that there is no conflict of interests regarding the publication of this paper.

\section{References}

[1] J. E. Mazur, "Mathematical models and the experimental analysis of behavior," Journal of the Experimental Analysis of Behavior, vol. 85, no. 2, pp. 275-291, 2006.

[2] D. C. Montgomery, Design and Experimental Analysis, John Wiley \& Sons, 5th edition, 2001.

[3] E. A. Mousa, "Effect of basicity on wüstite sinter reducibility under simulated blast furnace conditions," Ironmaking and Steelmaking, vol. 41, no. 6, pp. 418-429, 2014.

[4] E. A. Mousa, D. Senk, and A. Babich, "Influence of nut coke on the reducibility of basic sinter and acidic pellets," in Proceedings of the METEC InSteelCon 6th European Coke and Ironmaking Congress (ECIC '11), paper 8, VDEh, Düsseldorf, Germany, June 2011.

[5] E. Mousa, D. Senk, and A. Babich, "Reduction of pellets-nut coke mixture under simulating blast furnace conditions," Steel Research International, vol. 81, no. 9, pp. 706-715, 2010.

[6] E. A. Mousa, D. Senk, A. Babich, and H. W. Gudenau, "Influence of nut coke on iron ore sinter reducibility under simulated blast furnace conditions," Ironmaking and Steelmaking, vol. 37, no. 3, pp. 219-228, 2010.
[7] A. A. El-Geassy, "Influence of doping with $\mathrm{CaO}$ and/or $\mathrm{MgO}$ on stepwise reduction of pure hematite compacts," Ironmaking and Steelmaking, vol. 26, no. 1, pp. 41-52, 1999.

[8] K. S. Abdel Halim, M. Bahgat, H. A. El-Kelesh, and M. I. Nasr, "Metallic iron whisker formation and growth during iron oxide reduction: basicity effect," Ironmaking \& Steelmaking, vol. 36, no. 8, pp. 631-640, 2009.

[9] N. Shigematsu and H. Iwai, "Effect of $\mathrm{CaO}$ added with $\mathrm{SiO}_{2}$ and/or $\mathrm{Al}_{2} \mathrm{O}_{3}$ on reduction rate of dense wustite by hydrogen," ISIJ International, vol. 29, no. 6, pp. 486-494, 1989.

[10] M. Bahgat, K. S. Abdel Halim, H. A. El-Kelesh, and M. I. Nasr, "Enhancement of wüstite reducibility in blast furnace: reaction kinetics and morphological changes," Ironmaking and Steelmaking, vol. 39, no. 5, pp. 327-335, 2012.

[11] P. G. Coombs and Z. A. Munir, "Investigation of the reduction kinetics of wustite fine powders," Journal of Materials Science, vol. 25, no. 1, pp. 343-352, 1990.

[12] S. Ghali and E. A. Mousa, "Analysis of the reduction yield of synthetic iron oxide sinter reduced by $\mathrm{H}_{2}$ at $900-1100^{\circ} \mathrm{C}$ using factorial design approach," Steel Grips, 2014.

[13] E. A. Mousa and S. Ghali, "Factorial design analysis of reduction of simulated iron ore sinter reduced with CO gas at 1000$1100^{\circ}$ C," Ironmaking \& Steelmaking, 2014. 

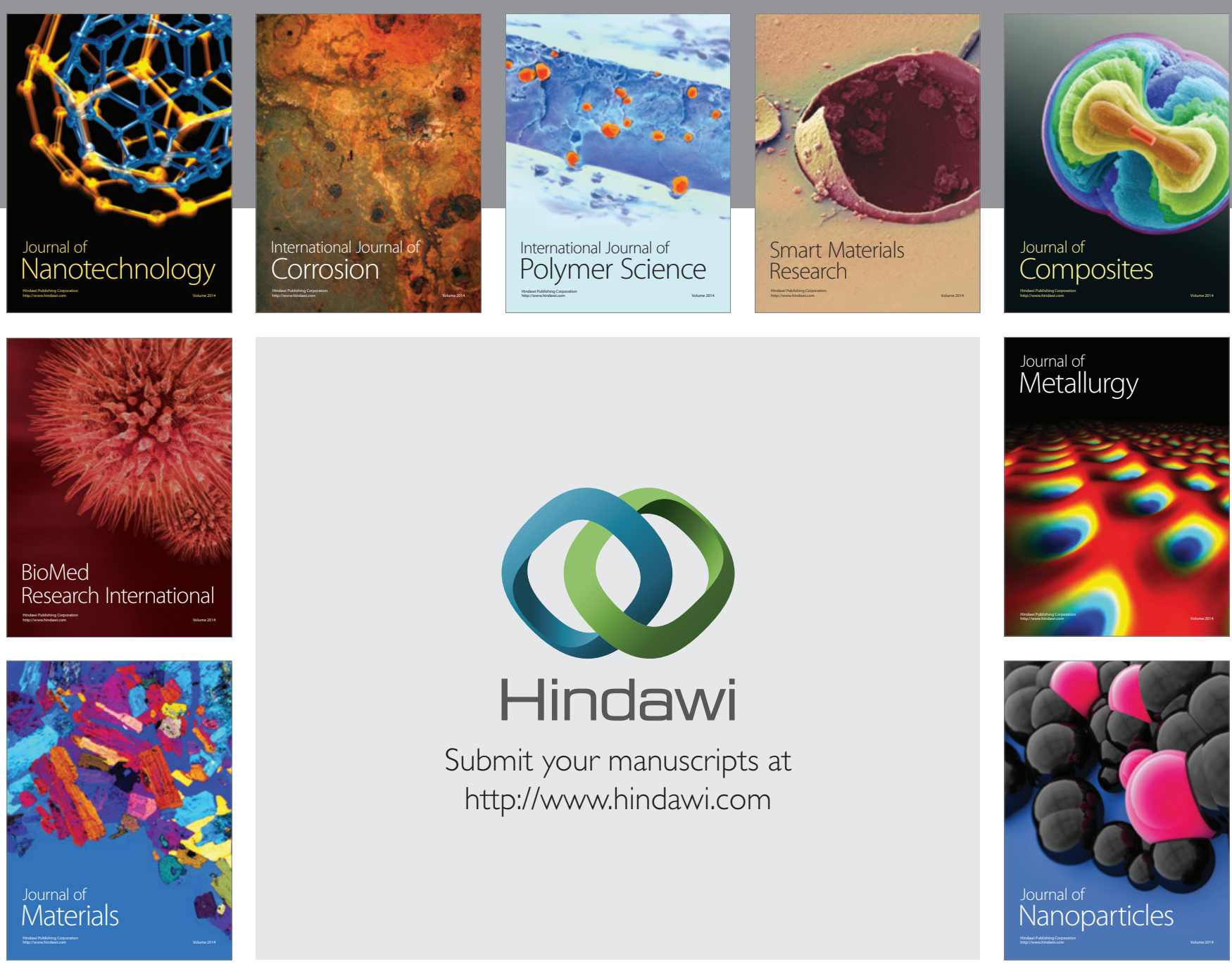

Submit your manuscripts at http://www.hindawi.com
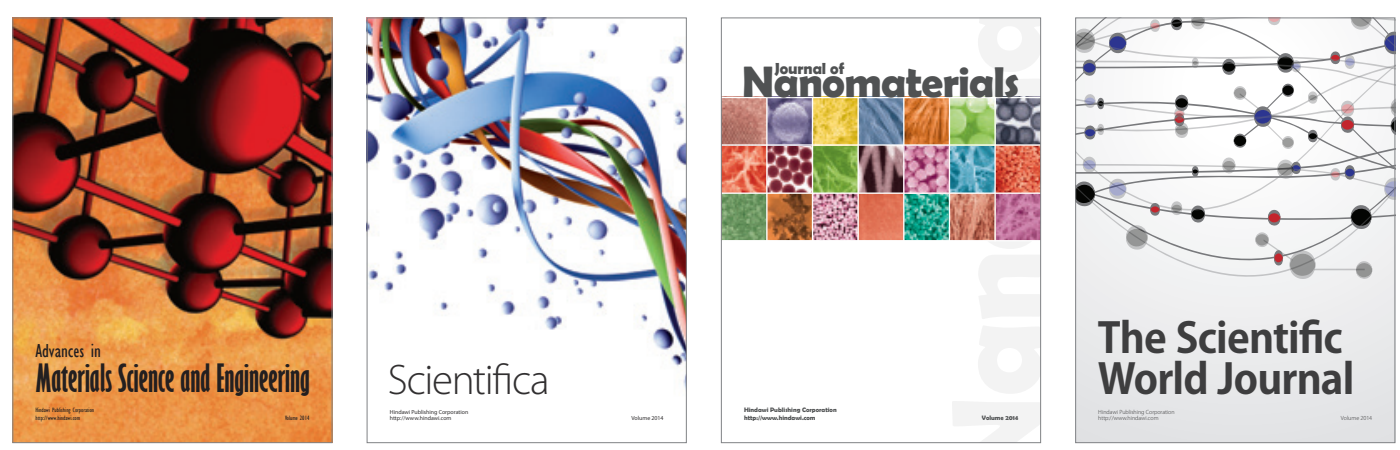

\section{The Scientific World Journal}
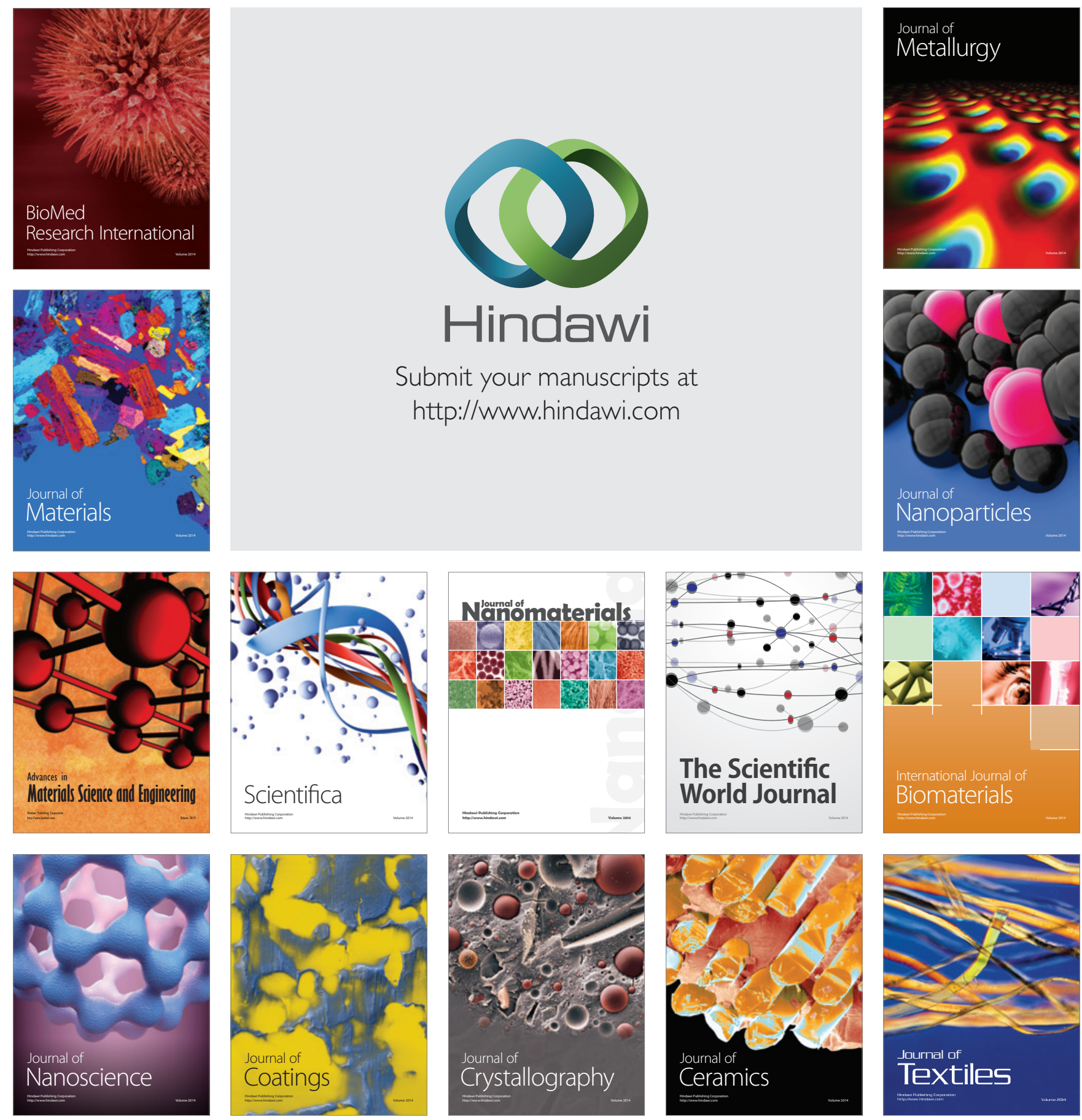